\title{
HTR Characterisation
}

\section{Hard-to-Reach Energy Users Annex}

\section{JULY 2020}

Kira Ashby \& Jennifer Smith (U.S.), Consortium for Energy Efficiency (CEE)

Dr. Sea Rotmann (NZ), HTR Annex

Dr. Luis Mundaca (SWE), Lund University

Dr. Aimee Ambrose (UK), Sheffield Hallam University 


\section{Contents}

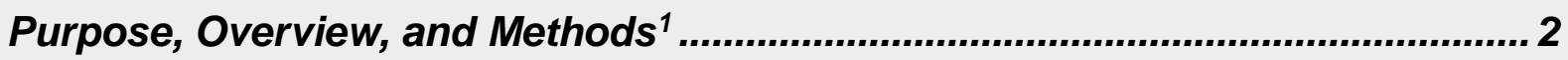

Definitions of Priority HTR Audience Characteristics........................................ 3

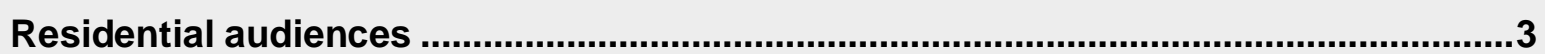

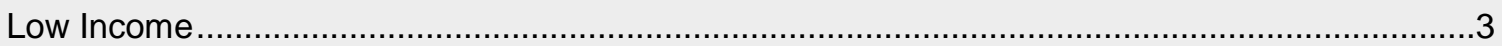

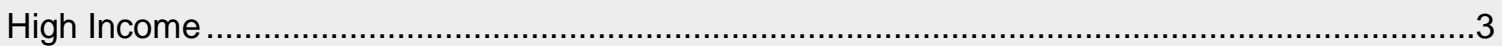

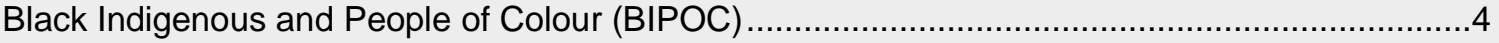

Commercial / Industrial Audiences .........................................................................................

Small Business / Enterprise (SMBs / SMEs) ................................................................. 3

Cross-Sector Audiences (applies to Residential and/or Commercial / Industrial) ........................4

HTR Audience Characteristics \& Barriers...........................................................5

Frequencies of HTR Audience Characteristics by Country.............................................5

Frequency of HTR Barriers by Country .....................................................................6

Common HTR Audience Characteristics and Related Barriers to Programme

Participation.............................................................................................................................7

Commonly-reported approaches to addressing HTR barriers in the U.S. and

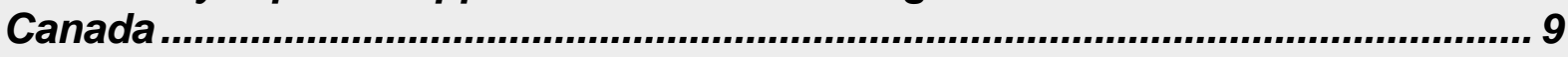

Links Across Audiences, Barriers, and Approaches .......................................... 9

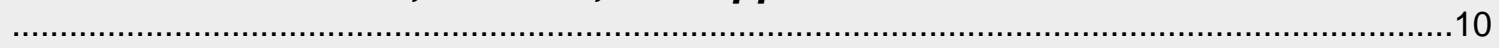

Cross-Country Comparisons and Transferability ............................................11

Metrics for Assessing Transferability ........................................................................11

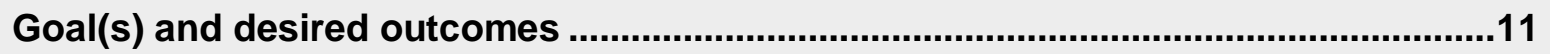

Prevalence of Technology Access ....................................................................................12

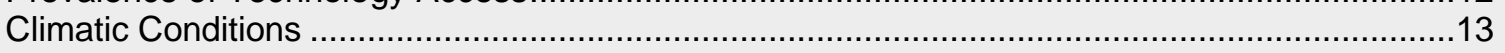

Age Distribution of Target Population …………………………………………………....13

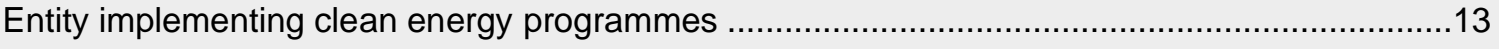

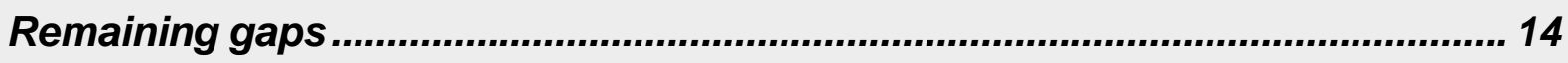

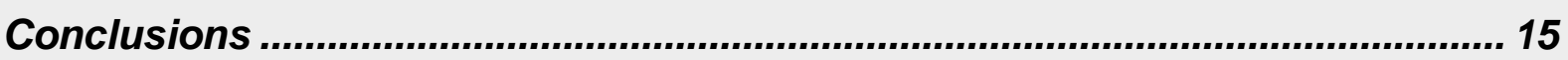

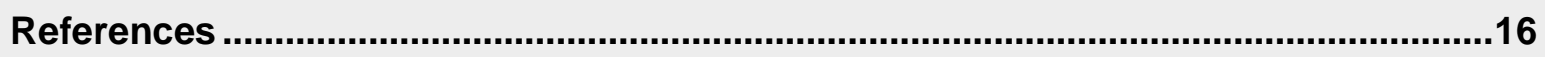

Suggested citation: Ashby, K., Smith, J., Rotmann, S., Mundaca, L. and A. Ambrose (2020a). HTR Characteristics. HTR Annex by Users TCP by IEA: Wellington.

https://doi.org/10.47568/3XR102 


\section{Purpose, Overview, and Methods ${ }^{1}$}

The purpose of this document is to outline a preliminary framework for characterising "Hardto-Reach" (HTR) energy users targeted for energy efficiency (EE) and demand response (DR) programmes in the U.S. and Canada. This document, which was requested by U.S. and Canadian participants, provides an overview of the various HTR audience segments, definitions, goals and intended outcomes of HTR efforts, and some initial approaches used to engage the HTR. Where possible, it also includes an initial analysis of cross-country transferability, and the metrics used to assess the applicability of international learnings.

The intended audience of this document is all country sponsors of the HTR project, albeit with a focus on the areas of interest to the Consortium for Energy Efficiency (CEE) members funding U.S. participation ${ }^{1}$. This is intended to be a living document, which evolves as additional data becomes available. Where applicable to U.S. and Canadian (CAN) programme administrators (PAs) and utilities, parallel data from the other participating countries - Sweden (SWE), New Zealand (NZ), and the United Kingdom (UK) - has been incorporated. For the purposes of this initial characterisation, the frequency with which a given HTR audience or barrier was mentioned in the data sources was used as a proxy for the priority level of those audiences and barriers. CEE sponsors agree this to be an acceptable, though limited, approximation (see Ashby et al, 2020 for more in-depth assessment of this research's limitations).

The data sources used in the development of this HTR Characterisation included:

- A Survey of CEE members and international HTR collaborators $(n=122$ from 21 countries, including 39 CEE members, completed September 2019).

- Stakeholder interviews $(n=49)$ with HTR experts from the U.S./CAN $(n=18)$, SWE $(n=11)$, NZ/Australia $(n=13)$, UK $(n=7)$.

- Input from U.S. HTR Workshop held in November 2019 (20 attendees from 5 countries).

- Input from CEE sponsors calls, Behaviour Committee meetings, and CEE Programme Meetings (May 2019 - June 2020).

- Literature review of international HTR literature (Rotmann et al, forthcoming).

The collected data from the survey, CEE member meetings, workshop, and stakeholder interviews were analysed by countries, HTR audience characteristics, barriers to better engagement, and approaches that have been (or could be) tried to more effectively engage them. This information was reviewed and summarised to identify and quantify common themes in the data.

\footnotetext{
${ }^{1}$ Please see User-Centred Energy Systems Technology Collaboration Programme by IEA (https://userstcp.org/), and related Annex on "Hard-to-Reach Energy Users" (https://userstcp.org/annex/hard-to-reach-energy-users/)
} 


\section{Definitions of Priority HTR Audience Characteristics}

One impetus behind the HTR Annex was to better define the various audiences included within the commonly-used, but often unclear, term "hard-to-reach". It is important to acknowledge that the term HTR may implicitly put the onus on the given audience(s) for being difficult to engage, whereas this project asserts that the focus ought to be on the "Behaviour Changers" (see Rotmann, 2016) and their (in)abilities to better reach them. In some places, the term HTR may be used synonymously with low income or otherwise "vulnerable" households, whereas this audience group can be a great deal more diverse. A key first step to assessing potential cross-country transferability of learnings is exploring whether stakeholders define and identify their common HTR audiences in a similar way. The HTR Literature review (Rotmann et al, forthcoming) provides much more detail on different HTR terminologies and their critiques, as well as in-depth analysis of the literature on audience definitions and characterisations via their demographics, psychographics, barriers and needs. Here, we only focus on the audiences that were most-commonly mentioned by our Annex stakeholders and experts.

\section{Residential audiences}

\section{Low Income}

In the U.S. and Canada, low income definitions are typically based on the federal poverty threshold (e.g. anyone is considered low income if their earnings are at or below $200-$ $225 \%$ of the federal poverty threshold, $\left.n=6^{2}\right)$ or the median state income $(<60-80 \%, n=2)$. In instances of geographically concentrated poverty, low income definitions are sometimes based on zip code and neighbourhood metrics $(n=3)$. This could be divided into additional sub-segments, e.g. low income renters were mentioned by U.S. participants. In NZ, holders of a "Community Service Card" automatically qualify as being low income households.

\section{High Income}

The definition of high(est)-income households, in general, involves the definition of arbitrary absolute values (e.g. based on a given GNI per capita figure) or the use of a measure based on a reference level of income (e.g. twice the median; Törmäletho, 2017). Acknowledging this caveat, the literature tends to define high-income households based on a specific quantile in the income distribution, and consequently pays particular attention to energy use resulting from disposable incomes that belong to the top decile or quintile ${ }^{4}$.

\section{Commercial / Industrial Audiences}

\section{Small Business / Enterprise (SMBs / SMEs)}

In the U.S. / CAN, the definition of small business with regards to energy efficiency programmes is most commonly based on annual energy consumption $(n=6)$, with varying cut offs, such as $<1.5$ million $\mathrm{kWh}$ or $40 \mathrm{~K}$ therms or $<5 \mathrm{~K}$ therms. Small businesses may also be defined as the number of employees ( $n=3$, such as $<50$ or 500 employees) or square footage of facility $\left(n=2\right.$, such as $<1000$ meters $\left.^{2}\right)$. Outside the U.S. and Canada, SMBs/SMEs are typically defined by the number of employees. In NZ, the cut-off is 20 employees for a small business, and the UK and EU differentiate between micro (0-9 employees) and small

\footnotetext{
${ }^{2}$ For the definitions listed here, $\mathrm{n}=$ the number of mentions of a given definition for a specific audience.

3 https://www.govt.nz/browse/health/financial-help/community-services-card/\#what-you-get

${ }^{4}$ https://ec.europa.eu/eurostat/documents/3888793/7882117/KS-TC-16-027-EN-N.pdf/42d637e3-1386-40e1845c-9aadad4ad2a1
} 
(10-49 employees) businesses. This could be divided into further sub-segments, such as rural SMBs/SMEs or those under indigenous ownership.

\section{Cross-Sector Audiences (applies to multiple sectors)}

\section{Black, Indigenous, and People of Colour (BIPOC)}

Individuals and communities who identify as Black, Indigenous (or First Nations), or People of Colour. This may include businesses owned or run by BIPOC individuals. In the U.S. and $\mathrm{CAN}^{5}$, indigenous communities are typically self-identified, including those living both on and off reservations. Māori are the indigenous people of Aotearoa NZ, and cultural identity is the underlying operational definition of an ethnic group, which can further include a common culture, religion, customs, ancestry, geographic origin, etc. In the UK, the term Black, Asian and Minority Ethnic (BAME) is more commonly used.

Underserved audiences are individuals, groups, or organisations:

- Who are marginalised or otherwise not served equitably in society;

- Who do not receive, or make use of, commensurate benefits in return for their ratepayer funding of programmes and services (this may be due to a lack of suitable programme offerings, or ability to participate in existing programmes);

- Whose "Participation Rate" or "Participant Distribution" is below a predetermined threshold, calculated as ${ }^{6}$ :

Participation Rate $=$ (\# of programme participants from energy user group)

/ (Total \# in energy user group)

Participant Distribution $=$ (\# of programme participants from energy user group) / (Total \# of participants in programmes)

\section{Rural residents and businesses}

In the U.S., census data categorises each zip code as rural or non-rural. Statistics NZ classifies rural as "Two categories of rural areas: rural centres and other rural. Rural centres are defined by population size, having a population of 300 to 999 in a reasonably compact area that services surrounding rural areas (district territory)."

\section{Multifamily Housing / Renters}

In the U.S. / CAN, multifamily housing (MFH) was defined as a housing building containing four or more units. More details are provided in the forthcoming literature review.

There was little definitional data for audiences such as immigrants / refugees; seniors / elderly; and mentally and physically disabled audiences, among others; however, these audiences are arguably somewhat more self-explanatory.

\footnotetext{
${ }^{5}$ Additional definitional details on First Nationals in Canada can be found here: https://www.rcaanccirnac.gc.ca/eng/1100100032275/1529354547314

${ }^{6}$ Levin, Emily, Elizabeth Palchak, Robert Stephenson, and Marti Frank (2019). The State of Equity Measurement: A Review of Practices in the Clean Energy Industry. VEIC: Vermont.
} 


\section{HTR Audience Characteristics \& Barriers}

\section{Frequencies of HTR Audience Characteristics by Country ${ }^{7}$}

This is an international project and, as such, the issue of potential cross-country transferability is an open question throughout. Although metrics for potential cross-country applicability are detailed later in this document, perhaps the first step is determining overlap (or lack thereof) in HTR audiences across countries. Figure 1a below illustrates the frequency of audience mentions by country, for each audience that was mentioned by at least three countries. In total, 30 characteristics of HTR audiences were identified. Of those 30 characteristics, 7 were mentioned by all four country categories (US / CAN data is combined) and another 9 characteristics were mentioned by at least three. Note, that only $\mathrm{NZ}$ mentioned convenience stores, drug and gang houses, day care centres, restaurants, shopping malls, single mothers, and mobile home communities. Both SWE and NZ mentioned complex organisations, ex-offenders, and minorities ${ }^{8}$ as HTR audiences, while both NZ and the UK mentioned energy-burdened communities and the US / CAN and NZ also mentioned moderate income audiences.

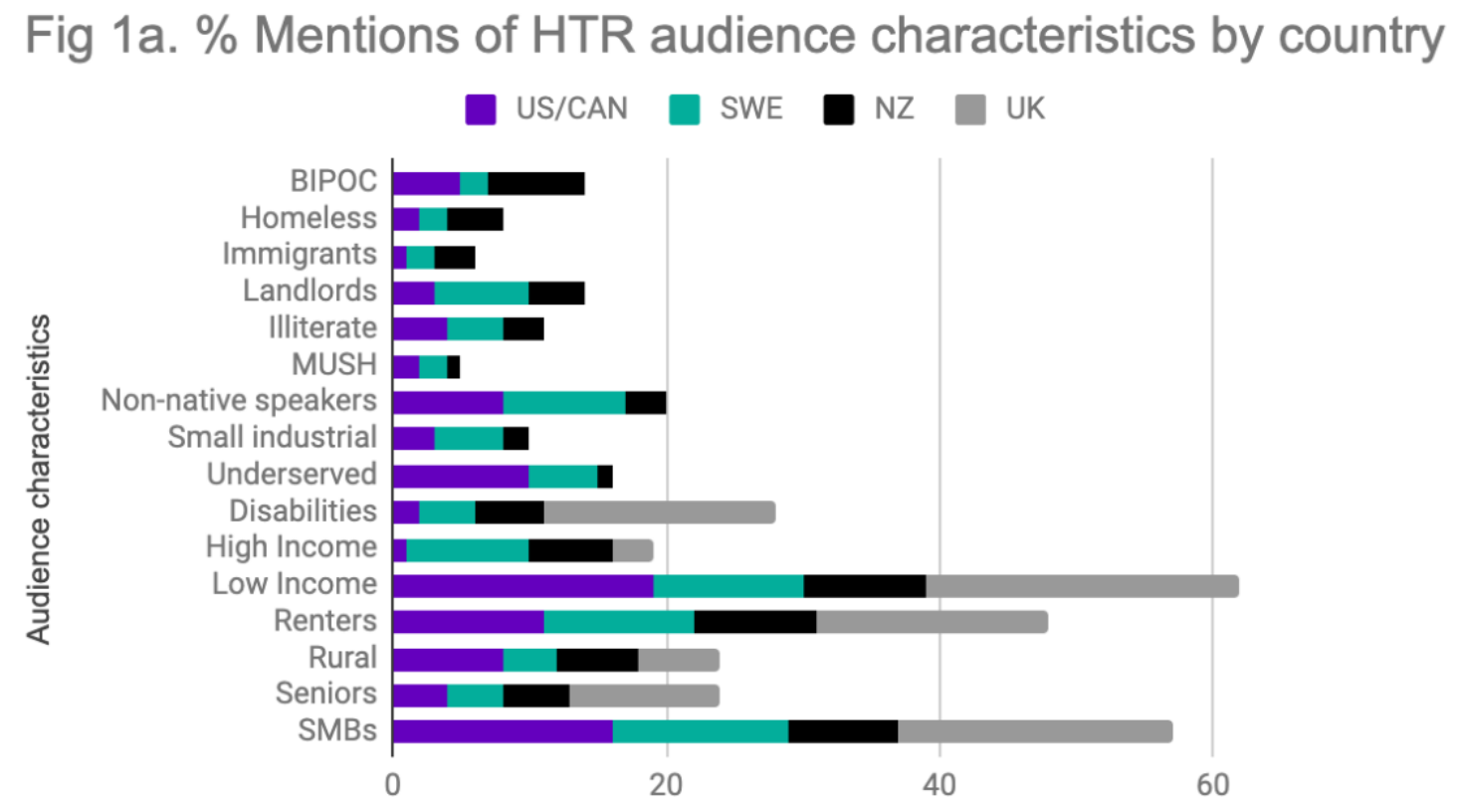

$\%$ Mentions

Figure $1 \mathrm{~b}$ shows the top three HTR audiences chosen by each country (Low Income Households, Renters and SMEs) by total numbers of mentions per country. Only Sweden ranked SMEs more often than low income households, and NZ and the UK ranked renters higher than SMEs.

\footnotetext{
${ }^{7} \mathrm{MUSH}=$ Municipalities, Universities, Schools, Hospitals; BIPOC = Black, Indigenous, and People of Colour 8 'Minorities' can mean slightly different things in different countries. For example, in NZ it includes other demographics than just ethnicity / race; and it is also considered a distinct characteristic from BIPOC (called "minor ethnic" and distinguishing between indigenous Māori and other ethnicities)
} 


\section{Fig 1b. Distribution of top 3 HTR audience mentions by country UK $\square$ US/CAN $\square$ SWE $\square$ NZ}

25

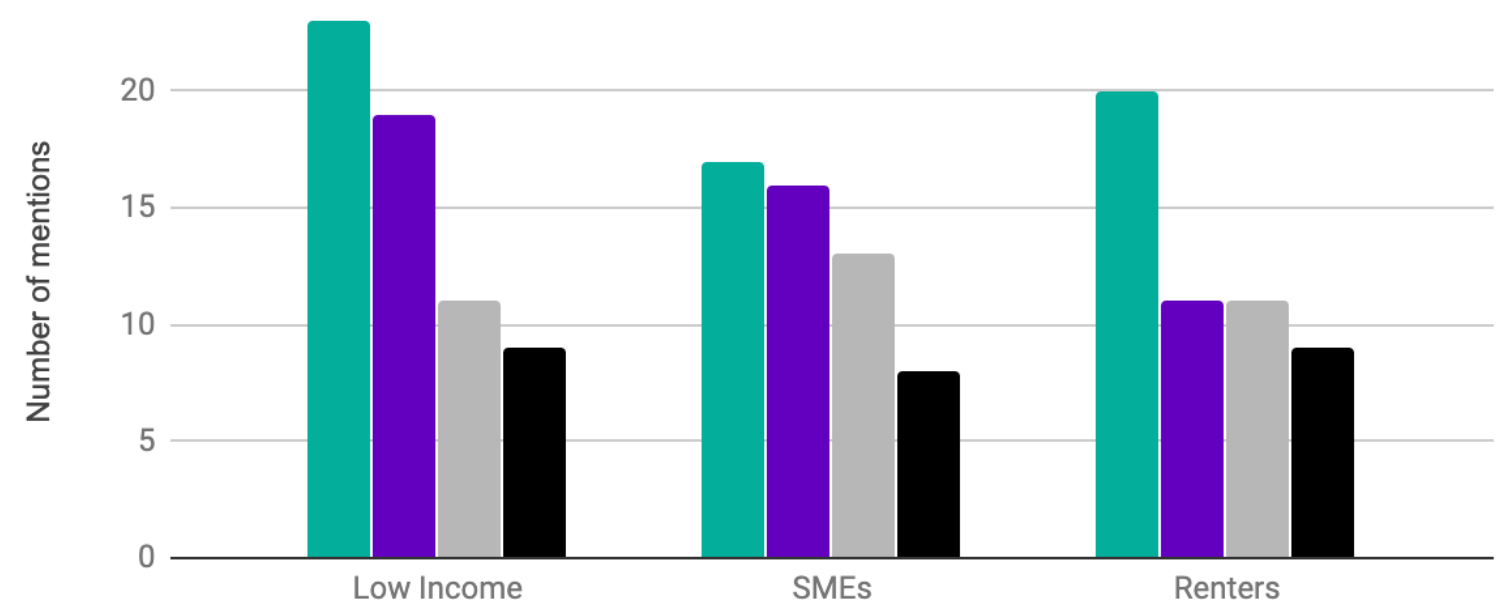

HTR audience groups

\section{Frequency of HTR Barriers ${ }^{9}$ by Country}

Given the diversity of HTR audiences, we hypothesised a similar diversity of key barriers to participation for HTR energy users (see Fig 2 below). However, in the U.S. / CAN, of all 18 barriers mentioned, just 3 barriers (cost, competing life priorities, and trust) accounted for more than a third of all barrier mentions. In NZ, $44 \%$ of barrier mentions were explained by the top 3 barriers of competing priorities, cultural differences, and the split incentive. In SWE, $50 \%$ of barrier mentions are explained by the top 3 barriers of cost, lack of motive (electricity prices too low to spur energy usage behaviour change), and the split incentive. In the UK, competing life priorities and health and safety concerns affecting ability to complete measures accounted for $44 \%$ of mentions, while self-efficacy and split incentive barriers accounted for another $25 \%$. Again, we only showed barriers that a minimum of three countries had mentioned. Other barriers that were mentioned included legislation and lack of motives (SWE); homogeneity of programme designers (U.S. / CAN); access to EE products and access to physical space; confusion around eligibility; and stigma (all U.S. / CAN and $\mathrm{NZ}$ ); as well as apathy (NZ and SWE). Overall, it is noteworthy that such a diversity of audiences appear to be experiencing only a handful of barriers with great frequency.

\footnotetext{
${ }^{9}$ Please note: the barriers listed here are barriers faced by HTR audiences, from the perspective of individuals or organisations ("Behaviour Changers") aiming to better engage HTR audiences in EE and behaviour change programmes.
} 


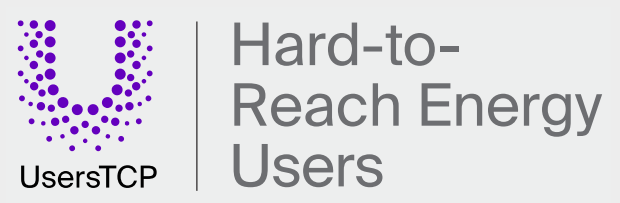

Fig $2 \%$ Mention of Barriers by different countries

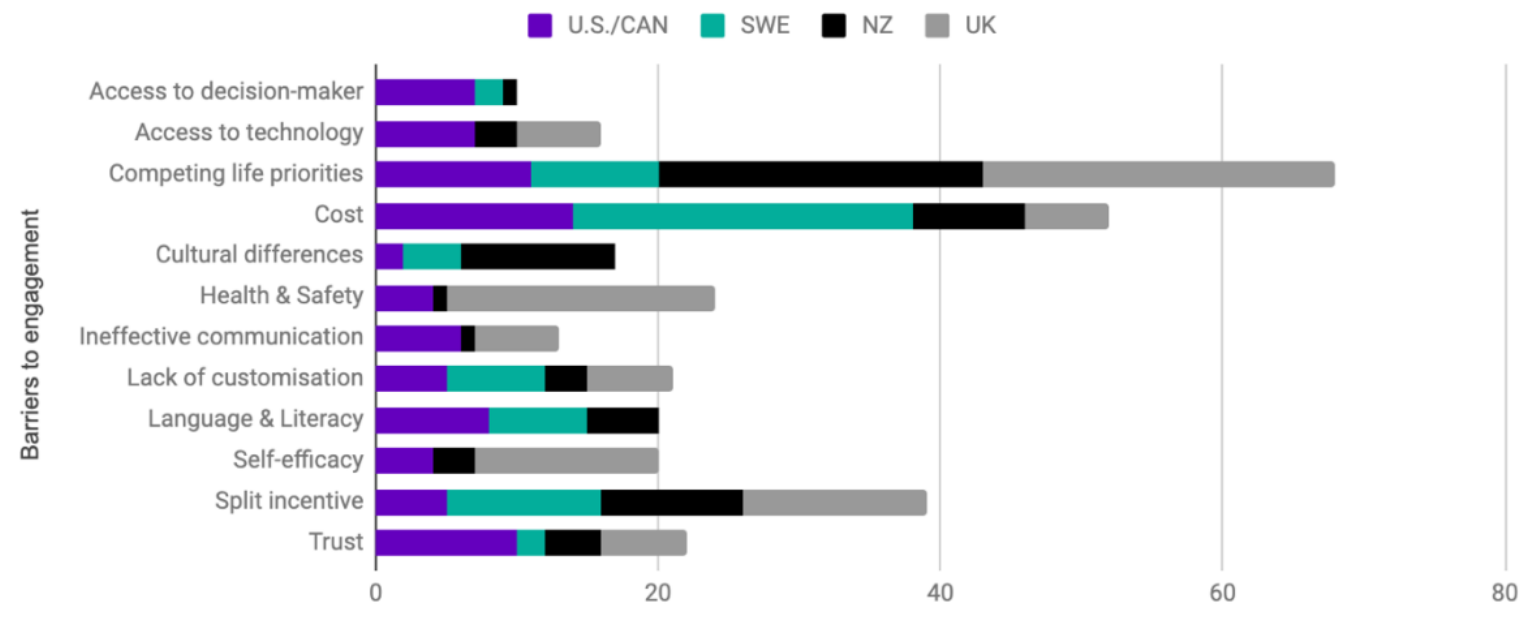

$\%$ Mentions

\section{Common HTR Audience Characteristics and Related Barriers to Programme Participation ${ }^{10}$}

The table below outlines a summary of the most common HTR audience characteristics and their related barriers, as mentioned by HTR experts surveyed and interviewed for this report.

10 The literature explicitly addressing definitions and barriers from a HTR perspective is limited and fragmented. Thus, some aspects of this table must be taken with due caution. 


\begin{tabular}{|c|c|c|c|}
\hline $\begin{array}{l}\text { Audience } \\
\text { Characteristic }\end{array}$ & Sector & Most common definition & Most common barrier/s \\
\hline Disabilities & Both & $\begin{array}{l}\text { Those with medical disabilities } \\
\text { (mental \& physical) }\end{array}$ & Access \\
\hline BIPOC & Both & $\begin{array}{l}\text { Self-identified Black, Indigenous, } \\
\text { People of Colour }\end{array}$ & Cultural differences \\
\hline High Income & Residential & Top income decile/quintile & $\begin{array}{l}\text { Lack of motivation, } \\
\text { Inadequate price mechan. }\end{array}$ \\
\hline Homeless (shelters) & Both $^{11}$ & $\begin{array}{l}\text { Transitional, episodic or chronic } \\
\text { homelessness }\end{array}$ & Cost \\
\hline Immigrants / refugees & Both & Not born in the country & Trust, language, cultural \\
\hline Landlords & Both & Owns and leases a property & Split Incentive \\
\hline Literacy limited & Residential & & Trust \\
\hline Low Income & Residential & $\begin{array}{l}\text { Income is less than or equal to twice } \\
\text { the federal poverty level }\end{array}$ & Cost \\
\hline Moderate Income & Residential & $\begin{array}{l}\text { Income is less than } 4 \text { times federal } \\
\text { poverty level }\end{array}$ & $\begin{array}{l}\text { Competing priorities; } \\
\text { ineffective comms; lack of } \\
\text { programme customisation }\end{array}$ \\
\hline MUSH & Commercial & $\begin{array}{l}\text { Municipalities, universities, schools, } \\
\text { and hospitals }\end{array}$ & Cost \\
\hline Non-native speakers & Both & $\begin{array}{l}\text { Those whose first-learned or primary } \\
\text { language is one other than the } \\
\text { nation's official language }\end{array}$ & Language \\
\hline Renters & Both & $\begin{array}{l}\text { Those who live or work in physical } \\
\text { space they do not own and instead } \\
\text { lease from the owner }\end{array}$ & Split incentive \\
\hline Rural & Both & Census bureau data designation & Access \\
\hline Seniors / Elderly & Residential & $\begin{array}{l}\text { Age } 65 \text { years and older in most } \\
\text { countries }\end{array}$ & Access to technology \\
\hline Small business & Commercial & $\begin{array}{l}\text { Those businesses who consume less } \\
\text { than some threshold of energy or } \\
\text { have below a certain number of } \\
\text { employees }\end{array}$ & Competing priorities; cost \\
\hline Small industrial & Commercial & $\begin{array}{l}\text { Those facilities too small to warrant } \\
\text { an account manager }\end{array}$ & Competing priorities; cost \\
\hline Underserved & Residential & $\begin{array}{l}\text { Anyone who is not currently being } \\
\text { served; disadvantaged zip codes; } \\
\text { identified by regulator based on } \\
\text { income, air quality, etc.; are } \\
\text { marginalised and/or do not receive } \\
\text { commensurate benefits in return for } \\
\text { their ratepayer funding of } \\
\text { programmes and services }\end{array}$ & $\begin{array}{l}\text { Lack of programme } \\
\text { customisation }\end{array}$ \\
\hline
\end{tabular}

\footnotetext{
${ }^{11}$ Homelessness does not automatically equate to rough sleeping or staying in shelters. The vast majority of homeless are transitional or episodic and often use energy in other people's residences (see Rotmann et al's forthcoming Literature Review for details)
} 


\section{Commonly-reported approaches to addressing HTR barriers in the U.S. and Canada}

Despite the diversity of HTR audiences, the commonly-reported approaches to better engaging HTR audiences in the U.S. and Canada can be grouped into three main categories. These include (in order of most to least frequently mentioned): modifying programme communications, partnering with local organisations, and increasing programme customisation. Examples of the specific programme approaches included within each of these broader categories are noted in Fig 3 below.

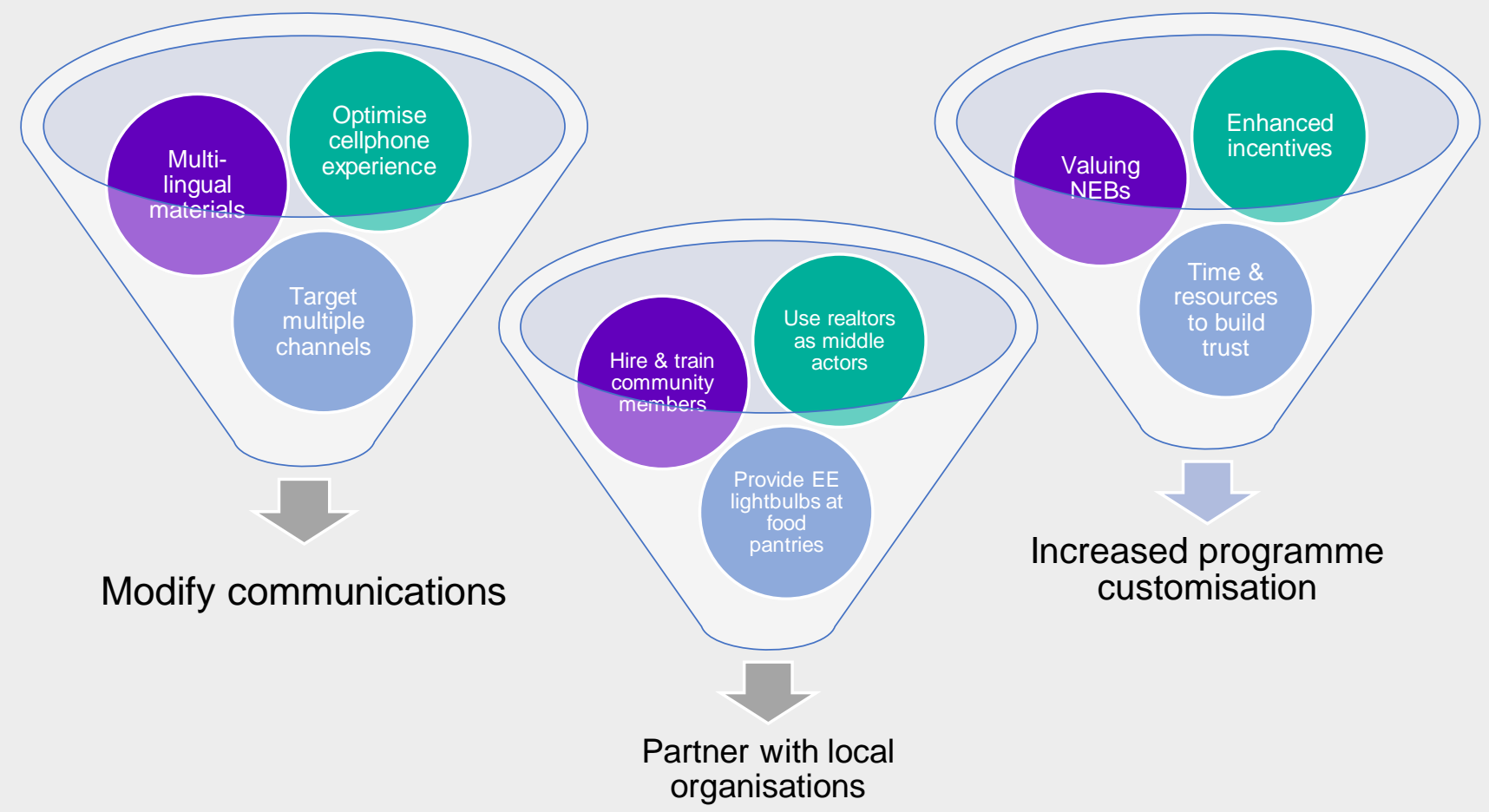

Fig 3. Three specific HTR programme approaches mentioned by experts in the U.S. and CAN (Source: CEE)

\section{Links Across Audiences, Barriers, and Approaches}

The connections between these broader approach categories and the audiences with which they are reportedly used are shown in the network map (Fig 4a) below. These relationships were quantified by tallying the number of instances one of these audiences and one of these barriers were mentioned concurrently. The size of the circles is proportional to the percentage of mentions for each audience, barrier, or approach category ${ }^{12}$, while the width of the line connecting the circles is proportional to the number of concurrent mentions between the two. 12 In other words: (\# mentions of Low Income / total \# of audience mentions) * 100 OR (\# mentions of cost / total
\# of barrier mentions) * 100 


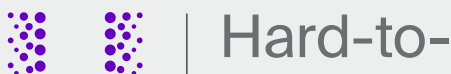 \\ Reach Energy \\ Userstcp Users}

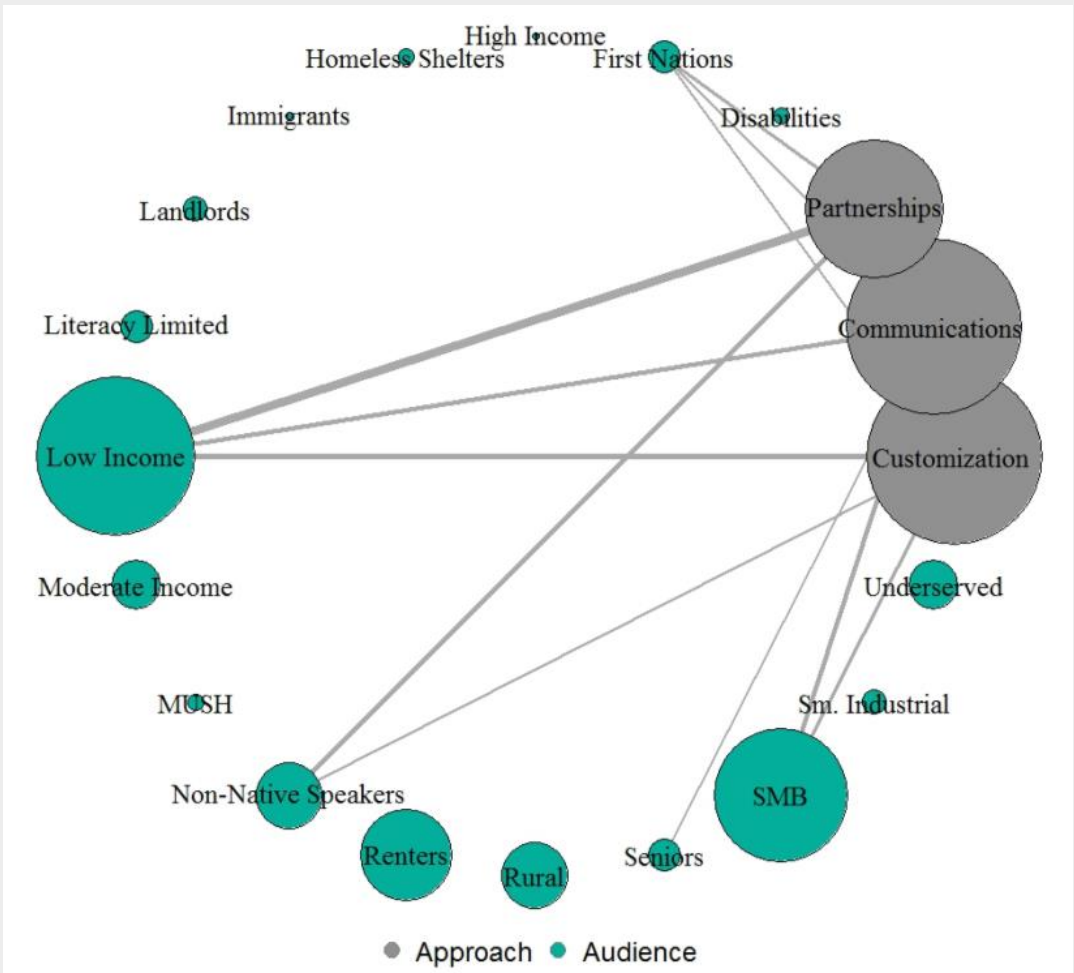

Fig 4a. Network map showing commonly-mentioned approaches in U.S./CAN and which audiences they are used with

Fig $4 \mathrm{~b}$ below illustrates how frequently the top five most commonly-mentioned audiences came up in connection with the top five most commonly-mentioned barriers. This was done by tallying the instance in which a category of approaches and a specific audience were mentioned concurrently by U.S. and Canadian EE programme administrators.

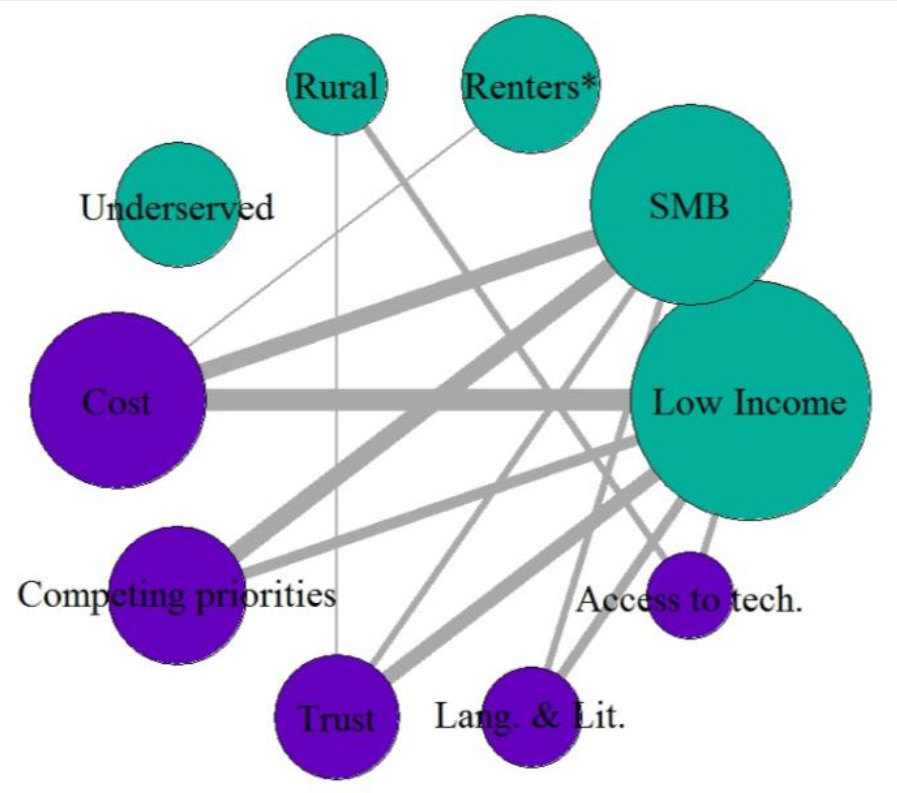

^The most common barrier for Renters was split incentive

Audience Barrier

Fig 4b. Network map showing commonly-mentioned audiences in U.S./CAN and which barriers they are associated with 


\section{Cross-Country Comparisons and Transferability}

\section{Metrics for Assessing Transferability}

Many factors could impact the transferability of international learnings to the U.S. and Canada. Considerations such as cultural differences (including overall weight given to environmental considerations) may be difficult to quantify, but CEE sponsors identified five quantifiable metrics to use in assessing cross-country comparability, each of which is detailed further in the sections that follow:

- goals and desired outcomes of the programme

- prevalence of technology access

- climatic conditions

- population age distribution

- entity that implements programmes in the given country (and associated strengths and weaknesses in terms of funding, authority level, and value placed on non-energy impacts)

There is substantial overlap across the U.S./CAN, SWE, and NZ/UK in terms of the goals and desired outcomes, prevalence of technology access (except for smart meters), and the relative age of each country's population. However, the climate in each country as well as the entity charged with designing and implementing energy programmes varies a great deal across countries, and sometimes even within countries. Additionally, opportunities for international HTR learnings will in large part be driven by the relative prevalence of the HTR audiences of interest in the respective countries. For instance, HTR audience learnings related to low income may be more robust from NZ and the UK, whereas SWE can shed greater light on the challenges of engaging geographically-remote energy users.

\section{Goal(s) and desired outcomes}

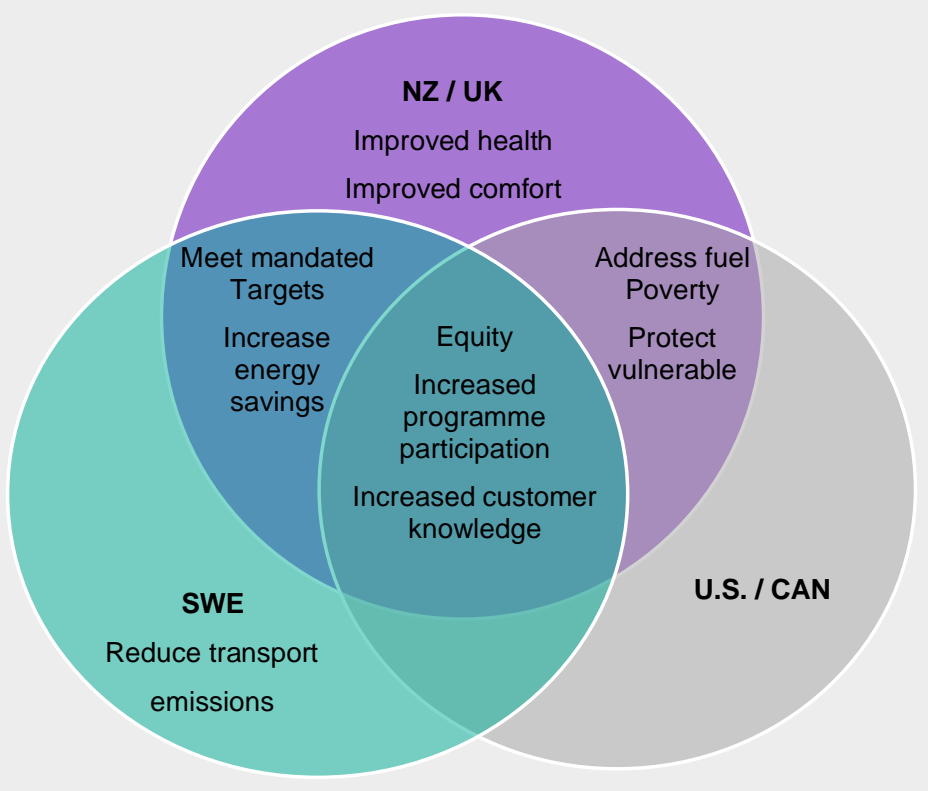

Fig 5. Venn diagram of desired goals and outcomes in participating countries 
There are several goals and desired programme and policy outcomes that are unique to one country or a pair of countries, as shown as a Venn diagram in Fig 5 above. Data from all countries emphasise equity, increased programme participation, and increased knowledge about EE as drivers of all efforts aimed at HTR audiences. Thus, programmes in other countries that include specific EE targets, equity aspects, increased participation, or increased EE knowledge as goals could be strong candidates for potential U.S. and Canadian transferability.

\section{Prevalence of Technology Access}

With access to internet, smart phones, and smart meters as an indicator of technology access, the five countries appear relatively comparable, with the exception that smart meter penetration is substantially lower in the U.S. and the UK than it is in SWE, NZ, and CAN. That said, smart meter penetration in the UK is currently ramping up and this gap may partially close by 2021 .

\begin{tabular}{|l|l|l|l|}
\hline Country & Internet access $\%$ & Smartphone ownership \% & Smart meter penetration \% \\
\hline SWE & $96 \%^{13}$ & $85 \%^{14}$ & $95 \%^{15}$ \\
\hline UK & $93 \%^{16}$ & $89 \%^{17}$ & $27 \%^{18}$ \\
\hline NZ & $89 \%^{19}$ & $80 \%^{20}$ & $72 \%^{21}$ \\
\hline U.S. & $90 \%^{22}$ & $81 \%^{23}$ & $47 \%^{24}$ \\
\hline CAN & $94 \%^{25}$ & $86 \%^{26}$ & $82 \%^{27}$ \\
\hline
\end{tabular}

In the U.S., smart meter access also varies dramatically by state. Overall, with the exception of access to smart meters, technology access across the countries is consistently high. Consequently, disparities in access to technology across countries are unlikely to inhibit cross-country transferability of findings.

\footnotetext{
${ }^{13}$ https://www.statista.com/statistics/377767/household-internet-access-in-sweden/

$14 \mathrm{https}: / / w w w . s t a t i s t a . c o m / s t a t i s t i c s / 494638 /$ smartphone-users-in-sweden/

15 https://iot-analytics.com/product/smart-meter-market-report-2019-2024/

16
}

https://www.ons.gov.uk/peoplepopulationandcommunity/householdcharacteristics/homeinternetandsocialmediaus age/bulletins/internetaccesshouseholdsandindividuals/2019

${ }_{18}^{17}$ https://www2.deloitte.com/uk/en/pages/technology-media-and-telecommunications/articles/the-market.html

https://assets.publishing.service.gov.uk/government/uploads/system/uploads/attachment_data/file/827813/2019_ Q2_Smart_Meters_Statistics_Report.pdf

19 https://www.statista.com/statistics/680688/new-zealand-internet-penetration/

$20 \mathrm{https}: / / w w w . s t a t i s t a . c o m / s t a t i s t i c s / 680711 /$ new-zealand-mobile-social-media-penetration/

$21 \mathrm{https}$ ://www.eranz.org.nz/fileadmin/user_upload/Smart_meters_summary_-_update_July_2017.pdf

22 https://www.pewresearch.org/internet/fact-sheet/internet-broadband/

23 https://www.pewresearch.org/internet/fact-sheet/mobile/

${ }^{24} \mathrm{https}$ ://www.utilitydive.com/news/smart-meter-deployments-slow-as-questions-emerge-over-cost-effectiveness$\mathrm{s} / 542941 /$

25 https://www150.statcan.gc.ca/n1/daily-quotidien/191029/dq191029a-eng.htm

26 https://www.statista.com/statistics/1035928/canada-smartphone-ownership-rate-by-province/

https://www.nrcan.gc.ca/sites/www.nrcan.gc.ca/files/canmetenergy/pdf/Smart\%20Grid\%20in\%20Canada\%20Re port\%20Web\%20FINAL\%20EN.pdf 


\section{Climatic Conditions}

Given the size of each of these countries, weather can vary highly even within country borders. Acknowledging this limitation, each country's capital is used as a point of comparison for average climate, with temperature as the main data point:

\begin{tabular}{|l|l|l|l|}
\hline Country & Capital & Average summer temperature & Average winter temperature \\
\hline SWE & Stockholm & $70^{\circ} \mathrm{F} / 21^{\circ} \mathrm{C}^{28}$ & $33^{\circ} \mathrm{F} / 1^{\circ} \mathrm{C}$ \\
\hline UK & London & $73^{\circ} \mathrm{F} / 23^{\circ} \mathrm{C}^{29}$ & $47^{\circ} \mathrm{F} / 8^{\circ} \mathrm{C}$ \\
\hline NZ & Wellington & $70^{\circ} \mathrm{F} / 21^{\circ} \mathrm{C}^{30}$ & $55^{\circ} \mathrm{F} / 13^{\circ} \mathrm{C}$ \\
\hline U.S. & Washington D.C. & $86^{\circ} \mathrm{F} / 30^{\circ} \mathrm{C}^{31}$ & $46^{\circ} \mathrm{F} / 8^{\circ} \mathrm{C}$ \\
\hline CAN & Ottawa & $78^{\circ} \mathrm{F} / 26^{\circ} \mathrm{C}^{32}$ & $25^{\circ} \mathrm{F} /-4^{\circ} \mathrm{C}$ \\
\hline
\end{tabular}

Clearly, there is distinct variation in average seasonal temperatures across the capitals of these countries. And yet these climate differences do not account for substantial weather variation across regions within the same countries, especially in larger countries such as the U.S. and Canada. As such, inter-country differences in weather could potentially hinder the transferability of some HTR findings.

\section{Age Distribution of Target Population}

All five countries ${ }^{33}$ have relatively young populations, particularly NZ:

\begin{tabular}{|l|l|l|}
\hline Country & Median age & Population 65 years and over \\
\hline SWE & 41 & $21 \%$ \\
\hline UK & 41 & $18 \%$ \\
\hline NZ & 37 & $16 \%$ \\
\hline U.S. & 39 & $17 \%$ \\
\hline CAN & 42 & $19 \%$ \\
\hline
\end{tabular}

Given the comparable median ages and proportion of overall population that is age 65 years and older, their relative age distributions would not be expected to limit potential transferability.

\section{Entity implementing clean energy programmes}

In the U.S., utilities or other energy efficiency programme administrators (EEPAs, or third party contractors hired by these companies) typically design and implement programmes. However, in Europe and NZ, and in some instances, Canada, it is more commonly the energy ministry or associated agencies (e.g. the Energy Efficiency and Conservation

\footnotetext{
28 https://en.climate-data.org/europe/sweden/stockholms-laen/stockholm-196/\#climate-table

$29 \mathrm{https}: / /$ en.climate-data.org/europe/united-kingdom/england/london-1/\#climate-table

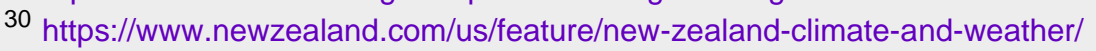

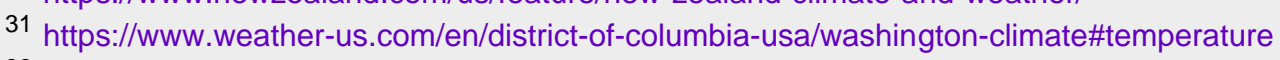

$32 \mathrm{https}: / /$ www.weather-ca.com/en/canada/ottawa-climate\#temperature

33 https://www.cia.gov/library/publications/resources/the-world-factbook/fields/343rank.html
} 
Authority in New Zealand or the Swedish Energy Agency) at the national, regional, or local level implementing energy programmes or policies.

There are substantial implications of this. For instance, in some cases government entities may have higher perceived authority relative to their utility counterparts, whereas for other HTR audiences (e.g. recent immigrants), government agencies may be associated with higher mistrust. More importantly, federal and state governments are tasked with the wellbeing of their citizens overall, which may well include - but certainly is not limited to potential benefits from EE. As a result, potential non-energy impacts such as health, comfort, etc. may be valued more highly in assessing the cost-benefit for an energy programme in places like SWE, the UK, or NZ than they would be in the U.S. and CAN. This is evident in the programme goals and desired outcomes in the Venn Diagram (Fig 5) earlier in this document. Of the metrics for cross-country comparability, the entity implementing EE programmes is perhaps the most variable across countries. Therefore, it is important to keep in mind the role of the implementing organisation in the success of any given approach before considering piloting that same approach with HTR audiences elsewhere.

\section{Remaining gaps}

Based on the learnings gathered thus far, we have identified a number of gaps in our knowledge that warrant additional exploration during Year 2 of this project, including:

- Prevalence: A key goal of this project is to assess the prevalence of various HTR audiences. Although existing literature provides initial estimates of the size of some of these groups (see some audience size estimates in Rotmann et al, forthcoming), it's often unclear what proportion of total energy users in a region or country are accounted for by these various audiences.

- Approaches: Now that we have made an initial assessment of potential transferability, it would be beneficial to continue to collect more details from all participating countries about successful approaches, and how they may be adapted for piloting elsewhere. Throughout Year 1 of this effort, we have begun collecting case studies of relevant HTR efforts, which will be gathered and synthesised during Year 2, and will provide a more in-depth look at approaches that have been successful (and not so successful) in different countries.

- Transferability: An ongoing assessment of transferability would be beneficial as future project data, including case studies on HTR efforts from participating countries, continues to shed new light on potential approaches that have worked well in certain locations. Exploration into the disparate policy contexts and potential implications on transferability would also be valuable.

- Assessment of aspects most conducive to addressing via international collaboration: This project has been clear from the outset that it cannot be all things to all people, that we have to start from a broad working definition of HTR (see Rotmann et al, forthcoming) and narrow our focus during data collection, and that it will be necessary to identify which HTR audiences and barriers may be more and less effective to address through this unique international collaboration approach. In Year 2, it will be important to further assess the relative value of different opportunities with an eye towards how we can get the most benefit from our collective effort. 


\section{Conclusions}

As articulated by CEE member sponsors, the top three objectives for better engaging HTR audiences in the U.S. and Canada are:

- increasing energy savings

- bolstering programme participation among underrepresented audiences

- fostering improved equity

Although the participating countries are geographically disparate, there are fundamental overlaps in their HTR goals. In fact, all funding countries' data confirm that fostering equity, increasing programme participation, and increasing people's knowledge of energy efficiency are key. Even where primary objectives do not overlap across countries, there are still shared secondary objectives-for instance, U.S. and CAN programmes share with the UK and NZ the secondary objectives of addressing low income customers and vulnerable populations. Similarly, U.S. and CAN programmes also share with SWE the secondary programme objective of meeting mandated energy reduction targets and increasing overall energy savings.

All project participants indicated that they are grappling with how to ensure that small businesses can benefit from EE programmes, how to help renters overcome the split incentive issue, and how to ensure that non-native speakers of the country's main language are engaged in EE efforts. These observed overlaps across the countries' most-mentioned audiences and barriers increase the likelihood of identifying transferable learnings and the opportunity for behavioural science experts from all participating countries to generate innovative engagement strategies for these groups and barriers.

Though it is important not to discount policy and cultural differences between the United States and Canada, European peers, and New Zealand, the number of commonalities across metrics for cross-country comparability is striking. Similarities in the goals and desired outcomes of energy programmes, population access to the internet and smartphones, and age distribution, suggest an optimistic outlook for transferability of international learnings. However, disparities in access to smart meters, differing climate patterns, and the diversity of organisations administering energy efficiency and conservation programmes across the countries will need to be considered in any efforts to adapt or pilot one country's approaches that have been deemed successful, in another. Admittedly, the picture will invariably be somewhat incomplete given that the countries involved are generally wealthy and mostly geographically concentrated in the Northern Hemisphere.

In Year 1, we have defined and narrowed down our focus on several key HTR audiences, their main characteristics, the barriers they face, and established a basis for international comparability and transferability. This knowledge will be the foundation for Year 2, as we begin to identify specific successful efforts and approaches to address priority HTR audiences or barriers and continue to assess potential transferability and scalability.

We want to thank all of our Annex sponsors, the Users TCP ExCo and the many HTR experts around the world who have so generously provided their insights and time. 


\section{References}

\section{SOURCES}

Ashby K. et al, 2020: Who are Hard-to-Reach energy users? Segments, barriers and approaches to engage them - ACEEE Summer Study for Energy Efficiency in Buildings: Monterey.

Rotmann S., 2016: How to create a "magic carpet for Behaviour Changers" - BEHAVE Conference: Coimbra

Rotmann, S., Mundaca, L., Castaño-Rosa, R., O'Sullivan, K., Ambrose, A., Marchand, R., Chester, M., Karlin, B. and K. Ashby (2020). Hard-to-Reach Energy Users: A critical review of audience characteristics and target behaviours. User-Centred Energy Systems TCP - HTR Annex: Wellington.

Törmäletho V.-M., 2017: High income and affluence: Evidence from the European Union statistics on income and living conditions (EU-SILC). EUROSTAT: Luxembourg. 49pp

\section{CONTACT}

Dr.Sea Rotmann: drsearotmann@gmail.com

\section{DISCLAIMER}

The International Energy Agency (IEA) is an intergovernmental organisation that works to shape a secure and sustainable future for all, through a focus on all fuels and all technologies, and analysis and policy advice to governments and industry around the world.

To facilitate global cooperation on energy technology, the IEA created the Technology Collaboration Programme (TCP). Today, the Users TCP is one of 38 TCPs each focused on a different topic. Together, they connect thousands of experts across government, academia and industry in 55 countries dedicated to advancing energy technology research and application.

The Users TCP is functionally and legally autonomous from the IEA. Views and findings of the Users TCP do not necessarily reflect those of the IEA. 